\title{
Retrospective analysis of high-dose intrathecal morphine for analgesia after pelvic surgery
}

\author{
Annette Rebel $M D^{1,2}$, Paul Sloan $\mathrm{MD}^{1}$, Michael Andrykowski PhD ${ }^{3}$
}

\begin{abstract}
A Rebel, P Sloan, M Andrykowski. Retrospective analysis of highdose intrathecal morphine for analgesia after pelvic surgery. Pain Res Manage 2011;16(1):19-26.
\end{abstract}

BACKGROUND: The effectiveness of intrathecal opioids (ITOs) for postoperative analgesia has been limited by reduced opioid dosing because of opioid-related side effects, most importantly respiratory depression. To overcome these limitations, high-dose intrathecal morphine was combined with a continuous intravenous (IV) postoperative naloxone infusion. The aim of the present chart analysis was to investigate the safety and efficacy of high-dose ITOs combined with IV naloxone compared with IV opioid analgesia alone.

METHODS: A retrospective chart analysis was performed on 121 female patients requiring major pelvic surgery. Ninety-eight patients received a single injection of high-dose ITOs before administration of typical general anesthesia, followed by an IV naloxone infusion at $5 \mu \mathrm{g} / \mathrm{kg} / \mathrm{h}$ started postITO and continued for $22 \mathrm{~h}$ postoperatively. Twenty-three patients were given IV morphine (IVM) for postoperative analgesia and served as a reference group. Postoperative pain relief, analgesic consumption and ability to ambulate were assessed for $48 \mathrm{~h}$ postoperatively. Treatment safety was assessed by monitoring opioid-related side effects and vital signs. Data are presented as mean \pm SD.

RESULTS: Mean ITOs given were morphine $1.1 \pm 0.2 \mathrm{mg}$ combined with fentanyl $49 \pm 6 \mu \mathrm{g}$. The mean worst pain visual analogue scale score in the first $12 \mathrm{~h}$ postoperatively was $0.2 \pm 0.90$ in the ITO group versus $4.3 \pm 3.0$ in the IVM group $(\mathrm{P}<0.05)$. On postoperative day 2 , the mean worst pain visual analogue scale score was only $1 \pm 1.8$ in the ITO group versus $4.1 \pm 2.6$ in the IVM group $(\mathrm{P}<0.05)$. Analgesic requirements were reduced in the ITO group. In the first $24 \mathrm{~h}$, the ITO group used $6.8 \pm 10.2$ morphine equivalents $(\mathrm{mg} I V)$ versus $76.1 \pm 44.4$ in the IVM group $(\mathrm{P}<0.05)$. All patients in the ITO group were able to ambulate in the first $12 \mathrm{~h}$ postoperatively compared with $17 / 23$ in the IVM group. There was a higher incidence of opioid-related sedation in the IVM group. Other opioidrelated side effects were infrequent and minor in both groups.

CONCLUSIONS: High-dose ITOs combined with a postoperative IV naloxone infusion provided excellent analgesia for major pelvic surgery. The IV naloxone infusion combined with high-dose ITOs appeared to control opioid side effects without affecting analgesia.

Key Words: Intrathecal opioids; Morphine; Naloxone; Spinal analgesia

\section{L'analyse rétrospective d'une analgésie par fortes doses de morphine intrathécale après une chirurgie pelvienne}

HISTORIQUE : L'efficacité des opioïdes intrathécaux (OIT) pour procurer une analgésie postopératoire est limitée par des doses réduites d'opioïdes en raison des effets secondaires de cette substance, notamment la dépression respiratoire. Pour vaincre ces limites, de fortes doses de morphine intrathécale ont été associées à une perfusion intraveineuse (IV) postopératoire continue de naloxone. La présente analyse des dossiers visait à explorer l'innocuité et l'efficacité de fortes doses d'OIT associées à la naloxone IV par rapport à l'analgésie opioïde IV seule.

MÉTHODOLOGIE : Les chercheurs ont procédé à une analyse des dossiers de 121 femmes qui devaient subir une chirurgie pelvienne majeure. Quatre-vingt-dix-huit patientes ont reçu une seule injection d'OIT à forte dose avant de se faire administrer une anesthésie générale classique, suivie d'une perfusion de $5 \mu \mathrm{g} / \mathrm{kg} / \mathrm{h}$ de naloxone amorcée après les OIT et poursuivie pendant une période postopératoire de 22 heures. Vingt-trois patientes ont reçu de la morphine IV (MIV) en analgésie postopératoire; elles ont servi de groupe de référence. Les chercheurs ont évalué le soulagement postopératoire de la douleur, la consommation d'analgésiques et la capacité de marcher pendant les 48 heures postopératoires. Ils ont évalué l'innocuité du traitement en surveillant les effets secondaires liés aux opioïdes et les signes vitaux. Les données sont présentées sous forme de moyenne \pm ÉT.

RÉSULTATS : Les doses moyennes d'OIT administrées étaient de $1,1 \mathrm{mg} \pm 0,2 \mathrm{mg}$ de morphine associé à $49 \mu \mathrm{g} \pm 6 \mu \mathrm{g}$ de fétanyl. L'indice moyen de l'échelle analogique visuelle de pire douleur pendant les 12 premières heures postopératoires était de $0,2 \pm 0,90$ dans le groupe d'OIT, par rapport à 4,3 $\pm 3,0$ dans le groupe de MIV $(\mathrm{P}<0,05)$. Lors du deuxième jour postopératoire, l'indice moyen de l'échelle analogique visuelle de pire douleur était seulement de $1 \pm 1,8$ dans le groupe d'OIT par rapport à 4,1 $\pm 2,6$ dans le groupe de MIV $(\mathrm{P}<0,05)$. Les besoins en analgésiques étaient réduits dans le groupe d'OIT. Pendant les 24 premières heures, le groupe d'OIT a utilisé 6,8 $\pm 10,2$ d'équivalents de morphine (mg IV) par rapport à $76,1 \pm 44,4$ dans le groupe de MIV $(\mathrm{P}<0,05)$. Toutes les patientes du groupe d'OIT pouvaient marcher pendant les 12 premières heures postopératoires, par rapport à 17 des 23 patientes du groupe de MVI. L'incidence de sédation liée aux opioïdes était plus élevée dans le groupe de MIV. Les autres effets secondaires liés aux opioïdes étaient peu courants et mineurs dans les deux groupes.

CONCLUSIONS : De fortes doses d'OIT associées à une perfusion postopératoire de naloxone IV fournissaient une excellente analgésie après une chirurgie pelvienne majeure. Cette association semble contrôler les effets secondaires des opioïdes sans nuire à l'analgésie.

control (2). Neuraxial opioid administration has gained increasing acceptance in the management of postoperative pain. Whereas epidural opioid analgesia has enjoyed widespread popularity, the intrathecal route has been labelled with inferior efficiency and safety, primarily because of the higher reported incidence of respiratory depression (3). The single-shot spinal injection should be attractive because it is simple, reliable, lacks catheter insertion, and costs less
Surveys indicate that more than $80 \%$ of patients experience moder$\checkmark$ ate to severe postoperative pain in spite of advances in pharmacology and sophisticated drug delivery systems (1). Inadequate postoperative pain relief can prolong recovery and length of hospitalization, increase health care costs and reduce patient satisfaction. The pain that accompanies surgical procedures generates great concern for patients and there is a growing demand from patients to optimize pain

${ }^{1}$ Department of Anesthesiology, University of Kentucky Medical Center, Lexington; ${ }^{2}$ Department of Anesthesiology, Pikeville Medical Center, Pikeville;

${ }^{3}$ Department of Behavioral Sciences, University of Kentucky Medical Center, Lexington, Kentucky, USA

Correspondence: Dr Annette Rebel, University of Kentucky Medical Center, 800 Rose Street, Lexington, Kentucky 40536, USA.

Telephone 859-323-5956, fax 859-323-1080, e-mail arebe2@email.uky.edu, website wildcatanesthesia.com 


\section{TABLE 1}

\section{Opioid equivalent conversion}

\begin{tabular}{lc}
\hline Medication & Opioid equivalents (OEs) \\
\hline Morphine & $1 \mathrm{mg}: 1 \mathrm{OE}$ \\
Butorphanol (Stadol $\left.{ }^{*}\right)$ & $1 \mathrm{mg}: 5 \mathrm{OE}$ \\
${\text { Hydromorphone }\left(\text { Dilaudid }^{\dagger}\right)}^{\text {Meperidine }\left(\text { Demerol }^{\ddagger}\right)}$ & $1 \mathrm{mg}: 6.6 \mathrm{OE}$ \\
Hydrocodone/acetaminophen (Lortab $^{\S}$ ) & $1 \mathrm{mg}: 0.13 \mathrm{OE}$ \\
Oxycodone/acetaminophen (Percocet $\left.^{\dagger}\right)$ & $1 \mathrm{mg}: 0.33 \mathrm{OE}$ \\
\hline
\end{tabular}

*Sandoz Pharmaceutical Inc, USA; ${ }^{\dagger}$ Purdue Pharma LP, USA; " sanofi-aventis US LLC; §UCB Pharma Inc, USA; "Endo Pharmaceuticals, USA

than its epidural or peripheral nerve block counterparts (4). However, the dosing and efficacy of intrathecal opioids (ITOs) remain limited due to fear of respiratory depression.

Therefore, to provide excellent postoperative pain control, we implemented a novel approach to allow high-dose intrathecal morphine by combining the ITO dose with a prophylactic intravenous (IV) naloxone infusion to control opioid-related side effects such as respiratory depression. We hypothesize that high-dose ITOs combined with IV naloxone provide better postoperative analgesia after major pelvic surgery than standard IV opioid therapy without causing major spinal opioid-related complications.

The technique has been published previously (5). In our previous report, we were not able to compare the intrathecal approach with conventional IV opioid therapy. The aim of the present analysis was to establish the safety profile and efficacy of high-dose ITOs combined with IV naloxone compared with IV opioid analgesia. Because this analgesic regimen was developed over several years, we chose a retrospective chart analysis to evaluate safety and efficacy.

\section{METHODS}

After institutional review board approval, a systematic retrospective review of the medical records was performed on patients undergoing a pubovaginal sling (PVS), or a combination of PVS with total vaginal hysterectomy (TVH) in the time period from January 1, 2004, to December 31, 2006 at Pikeville Medical Center (Kentucky, USA). Because the technique was developed and modified over several years, the observation time period was chosen to avoid any modifications in the described technique due to system adjustments, and still allow inclusion of the maximal available patient collective for analysis. The institutional review board waived the requirement for written consent. All patients undergoing the surgical procedure of interest were reviewed. A total of 121 patients were identified. The medical records were reviewed for procedure-related data (anesthesia technique/ operating room (OR) time/timing and dosing of the intrathecal medication), anesthesia recovery time, postoperative use and method of pain control for the first $48 \mathrm{~h}$, quality of pain control in the first $48 \mathrm{~h}$ postoperatively (visual analogue scale [VAS] pain scores and patient request for analgesics), vital signs (respiratory rate, heart rate, noninvasive mean blood pressure and pulse oximetry saturation) measured at $6 \mathrm{~h}, 12 \mathrm{~h}, 18 \mathrm{~h}, 24 \mathrm{~h}, 36 \mathrm{~h}$ and $48 \mathrm{~h}$ postintrathecal placement, length of hospital stay, and opioid- and nonopioid-related events during the first $48 \mathrm{~h}$ postoperatively.

For intra- and postoperative analgesia, all patients received either a single-shot ITO dose or IV opioids. After obtaining surgical consent, all patients received $2 \mathrm{mg}$ IV midazolam for premedication.

\section{ITO group}

The technique was previously reported in detail by Rebel et al (5). Briefly, patients receive a single-shot intrathecal injection of preservative-free morphine, preservative-free fentanyl, $100 \mathrm{mg}$ dextrose $(1 \mathrm{~mL}$ of a $10 \%$ solution) and $0.2 \mathrm{mg}$ adrenaline to a total volume of $3 \mathrm{~mL}$ to $3.5 \mathrm{~mL}$ using a sterile technique with a 25 -gauge or 27 -gauge Whitaker needle before anesthesia induction; no local anesthetic was added to the intrathecal medication. General anesthesia was then induced. The anesthetic included endotracheal intubation and neuromuscular paralysis. Intraoperatively or at the conclusion of the procedure (60 min to $120 \mathrm{~min}$ after intrathecal placement), a naloxone infusion $(20 \mu \mathrm{g} / \mathrm{mL})$ was started and maintained at $5 \mu \mathrm{g} / \mathrm{kg} / \mathrm{h}$ for $22 \mathrm{~h}$ postintrathecal placement. If spontaneous respiration did not resume at the end of the procedure after reversal of the neuromuscular blockade, a bolus of $0.2 \mathrm{mg}$ to $0.4 \mathrm{mg}$ IV naloxone was administered.

\section{IV morphine group}

Patients refusing intrathecal injection or with contraindications to neuraxial injection were treated with IV opioids for postoperative analgesia. The surgical procedure, including endotracheal intubation and neuromuscular paralysis, was performed under general anesthesia. Intraoperative opioids (fentanyl, morphine or meperidine) were given for analgesia. Postoperative pain control was provided by IV patientcontrolled analgesia (IVPCA) with $1 \mathrm{mg}$ morphine every $6 \mathrm{~min}$ to $10 \mathrm{~min}$, no basal rate and a lockout dose of $10 \mathrm{mg} / \mathrm{h}$. If the patient was not a candidate for IVPCA, nurse-controlled IV injections of morphine or meperidine were used for postoperative analgesia depending on the patient response and the preferences of the surgical service.

Postoperatively, all patients were observed in the postanesthesia recovery unit (PACU) until discharge criteria according to the Aldrete score were met (6). If necessary, additional analgesics (ketorolac or opioids) were given for pain control. Patients in the ITO group were discharged to the nursing floor with standardized postoperative orders (Appendix). A standard order set was developed for ITO (Appendix) and an anesthesia provider was continuously available. After $22 \mathrm{~h}$ postintrathecal placement, the naloxone infusion was discontinued. Postoperative analgesia was assumed by the primary surgeon using oral analgesics (hydrocodone/acetominophen or oxycodone/acetominophen) and IV morphine (IVM) for breakthrough pain. In the IVM group, the standardized orders were not used. The patients received opioids (morphine or meperidine) by IVPCA, as ordered by the anesthesia provider or surgeon. If analgesia was not sufficient even after a dose increase and patient-controlled analgesia adjustments, hydromorphone was used. Postoperative analgesia was managed by the primary surgical service.

\section{Target parameters}

The primary objective of the present analysis was to assess the occurrence of opioid-related events, which included respiratory depression (with or without need for intervention), hemodynamic stability and pruritus. The secondary goal was to assess the efficacy of high-dose ITOs, evaluated by need for additional analgesics, quality of pain control determined by patient-reported VAS scores $(0=$ no pain; $10=$ worst pain possible), and patient comfort as expressed by the ability to ambulate and need for hospitalization/discharge time. The need for additional analgesics was assessed by different approaches:

1. Timing of the first opioid postoperatively: The time interval for the ITO group was expressed in minutes after intrathecal placement; for the IVM group, it was expressed in minutes after the surgery started. For all ITO patients, the spinal injection occurred within $20 \mathrm{~min}$ of start of surgery. Thus, the start time for the first opioid postoperatively was very similar for both the ITO and IVM groups. Because opioid choice depended on the anesthesia provider and surgeon preference, different analgesics were used postoperatively. To comparatively assess the amount of opioids, opioid equivalents were calculated based on published opioid equivalent tables and adjusted to a relative value compared with $1 \mathrm{mg}$ IVM (Table 1) $(7,8)$.

2. The opioid equivalents were calculated for the first $24 \mathrm{~h}$ postintrathecal placement (including PACU stay) and for the second postoperative day ( $24 \mathrm{~h}$ to $48 \mathrm{~h}$ postintrathecal placement).

3. Nonopioid analgesic use was assessed using the cumulative ketorolac dose in $24 \mathrm{~h}$ and from $24 \mathrm{~h}$ to $48 \mathrm{~h}$.

Opioid-related side effects: Sedation (observed by nursing staff), respiratory depression (according to vital signs or nursing note, or 
TABLE 2

Demographic data for all patients according to surgical group and analgesic treatment

\begin{tabular}{lcccc}
\hline & $\begin{array}{c}\text { Group 1: } \\
\text { ITO (PVS) } \\
(\mathbf{n}=\mathbf{5 8})\end{array}$ & $\begin{array}{c}\text { Group 2: } \\
\text { IVM (PVS) } \\
(\mathbf{n}=\mathbf{1 0})\end{array}$ & $\begin{array}{c}\text { Group 3: ITO } \\
\text { (PVS/TVH) } \\
(\mathbf{n}=\mathbf{4 0})\end{array}$ & $\begin{array}{c}\text { Group 4: } \\
\text { IVM (PVSI } \\
\text { TVH) }(\mathbf{n}=13)\end{array}$ \\
\hline Age, years & $53 \pm 11$ & $54 \pm 10$ & $48 \pm 63$ & $46 \pm 11$ \\
Weight, kg & $81.9 \pm 16.6$ & $87.3 \pm 21.6$ & $75.9 \pm 16.0$ & $85.0 \pm 17.0$ \\
Body mass index, & $31.3 \pm 5.8$ & $32.6 \pm 8.4$ & $28.5 \pm 6.1$ & $31.2 \pm 5.9$ \\
$\quad$ kg/m & & & & \\
ASA status & $2.5 \pm 0.6$ & $2.9 \pm 0.3^{*}$ & $2.1 \pm 0.5$ & $2.2 \pm 0.6$ \\
$\begin{array}{l}\text { OR time, min } \\
\text { PACU time, min }\end{array}$ & $97.1 \pm 19.6$ & $104.6 \pm 27.5$ & $152.5 \pm 25.8$ & $166.9 \pm 25.1$ \\
Length of & $57.6 \pm 22.8$ & $58.1 \pm 24.3$ & $65.5 \pm 21.3$ & $64.2 \pm 20.9$ \\
$\quad$ & $1800 \pm 1203$ & $1804 \pm 668$ & $2923 \pm 698$ & $3215 \pm 764$ \\
\hline
\end{tabular}

Data presented as mean $\pm S D$. ${ }^{*} P<0.05$. ASA American Society of Anesthesiologists physical status classification; ITO Intrathecal opioid; IVM Intravenous morphine; OR time Time from incision to dressing from surgical procedure; PACU time Time from arrival to discharge from postanesthesia care unit; PVS Pubovaginal sling; TVH Total vaginal hysterectomy

requiring naloxone intervention), nausea/vomiting (according to nursing note or requiring antiemetics) and pruritus were reported to occur.

Statistical data analysis

All data for continuous variables are expressed as mean \pm SD, while data for categorical variables are expressed as percentages. Primary analyses involved separate comparisons of the PVS+ITO and PVS+IVM groups, and the PVS/TVH+ITO and PVS/TVH+IVM groups with regard to a variety of clinical outcome variables. Group means for continuous variables were compared using Student's $t$ test for independent samples. When appropriate, group means for continuous clinical outcome variables were compared using ANCOVA to control for group differences in demographic or clinical variables. Group comparisons for categorical variables were made using the $\chi^{2}$ test. Group differences in time to first postoperative opioid dose were compared using Kaplan-Meier analyses. Time to first postoperative opioid dose was defined as the elapsed time between first postoperative administration of opioids and time of intrathecal analgesia placement (PVS+ITO and PVS/TVH+ITO groups) or time of surgical incision (PVS+IVM and PVS/TVH+IVM groups). The criterion for statistical significance for all analyses was set at $\mathrm{P}<0.05$.

\section{RESULTS}

A total of 121 female patients were identified who underwent PVS or PVS/TVH at Pikeville Medical Center in the time period from January 1, 2004, to December 31, 2006, with the following distribution: 53 patients underwent PVS/TVH and 68 patients underwent PVS alone. The biological data for each group and group sizes are shown in Table 2.

No differences in vital signs were observed among the groups during the observation period (Table 3). Respiration rate did not differ in the ITO groups compared with the IVM groups for either surgical procedure. Because patients receiving only IV opioids were not routinely monitored with pulse oximetry postoperatively, pulse oximetry data in the IVM groups are incomplete.

Results for PVS surgery (groups 1 and 2)

There were 58 patients in the ITO group and 10 patients in the IVM group. The ITO (PVS) group received a mean dose of $1.1 \pm 0.1 \mathrm{mg}$ morphine and $49 \pm 6 \mu \mathrm{g}$ fentanyl intrathecally before anesthesia induction. There were no differences in OR and PACU time between the control (IVM) and treatment group. In general, much better pain relief was observed (Table 4 and Figures 1 and 2) in the ITO group. The worst VAS pain score in the first $12 \mathrm{~h}$ postoperatively was
TABLE 3

Vital signs for all patients according to surgical group and analgesic treatment

\begin{tabular}{|c|c|c|c|c|}
\hline & $\begin{array}{c}\text { Group 1: } \\
\text { ITO (PVS) } \\
(n=58)\end{array}$ & $\begin{array}{c}\text { Group 2: } \\
\text { IVM (PVS) } \\
(n=10)\end{array}$ & $\begin{array}{c}\text { Group 3: ITO } \\
\text { (PVS/TVH) } \\
(n=40)\end{array}$ & $\begin{array}{c}\text { Group 4: IVM } \\
\text { (PVS/TVH) } \\
(n=13)\end{array}$ \\
\hline HR $6 \mathrm{~h}$ & $75 \pm 14$ & $82 \pm 11$ & $77 \pm 11$ & $77 \pm 14$ \\
\hline HR $12 \mathrm{~h}$ & $79 \pm 15$ & $92 \pm 14$ & $81 \pm 12$ & $80 \pm 18$ \\
\hline HR 18 h & $79 \pm 13$ & $91 \pm 7$ & $80 \pm 13$ & $81 \pm 16$ \\
\hline HR 24 h & $78 \pm 4$ & $89 \pm 14$ & $80 \pm 11$ & $82 \pm 14$ \\
\hline HR 36 h & & & $84 \pm 12$ & $85 \pm 17$ \\
\hline HR 48 h & & & $82 \pm 12$ & $82 \pm 11$ \\
\hline Sat $6 \mathrm{~h}$ & $98 \pm 2$ & $92^{*}$ & $99 \pm 1$ & $97 \pm 4^{*}$ \\
\hline Sat $12 \mathrm{~h}$ & $98 \pm 2$ & $92^{*}$ & $98 \pm 2$ & $98 \pm 1^{*}$ \\
\hline Sat $18 \mathrm{~h}$ & $97 \pm 2$ & $\mathrm{~N} / \mathrm{A}$ & $98 \pm 1$ & N/A \\
\hline Sat $24 \mathrm{~h}$ & $97 \pm 2$ & N/A & $98 \pm 1$ & N/A \\
\hline Sat $36 \mathrm{~h}$ & & & $99 \pm 1$ & N/A \\
\hline Sat $48 \mathrm{~h}$ & & & $99 \pm 1$ & N/A \\
\hline RR 6 h & $19 \pm 1$ & $18 \pm 3$ & $19 \pm 2$ & $19 \pm 2$ \\
\hline RR 12 h & $20 \pm 2$ & $19 \pm 2$ & $19 \pm 2$ & $20 \pm 2$ \\
\hline RR 18 h & $20 \pm 1$ & $19 \pm 1$ & $19 \pm 1$ & $19 \pm 2$ \\
\hline RR 24 h & $20 \pm 1$ & $21 \pm 2$ & $19 \pm 1$ & $20 \pm 1$ \\
\hline RR 36 h & & & $20 \pm 1$ & $19 \pm 1$ \\
\hline RR 48 h & & & $19 \pm 2$ & $19 \pm 1$ \\
\hline MAP $6 \mathrm{~h}$ & $81 \pm 15$ & $85 \pm 13$ & $78 \pm 9$ & $88 \pm 10$ \\
\hline MAP $12 \mathrm{~h}$ & $77 \pm 15$ & $84 \pm 11$ & $71 \pm 8$ & $84 \pm 12$ \\
\hline MAP $18 \mathrm{~h}$ & $77 \pm 14$ & $82 \pm 8$ & $75 \pm 10$ & $76 \pm 6$ \\
\hline MAP $24 \mathrm{~h}$ & $75 \pm 20$ & $87 \pm 14$ & $77 \pm 11$ & $76 \pm 5$ \\
\hline MAP 36 h & & & $84 \pm 11$ & $85 \pm 14$ \\
\hline MAP $48 \mathrm{~h}$ & & & $86 \pm 10$ & $81 \pm 10$ \\
\hline
\end{tabular}

Data are presented as mean $\pm S D$. *Insufficient sample number to calculate SD and statistical testing. HR Heart rate in beats/min; ITO Intrathecal opioid; IVM Intravenous morphine; MAP Noninvasive mean arterial blood pressure in $\mathrm{mmHg}$; N/A Not applicable (not measured); PVS Pubovaginal sling; RR Respiration rate in breaths/min; Sat Pulse oximetry saturation in \%; TVH Total vaginal hysterectomy

\section{TABLE 4}

Analgesic dosing and effects for pubovaginal sling (PVS) and total vaginal hysterectomy (TVH)/PVS groups

\begin{tabular}{lccc}
\hline Group PVS (groups 1 and 2) & ITO (n=58) & IVM (n=10) & P \\
\hline Intrathecal morphine, $\mathrm{mg}$ & $1.1 \pm 0.1$ & 0 & N/A \\
Intrathecal fentanyl, $\mu \mathrm{g}$ & $49 \pm 6$ & 0 & N/A \\
Intraoperative fentanyl IV, $\mathrm{g}$ & $48 \pm 54$ & $170 \pm 92$ & \\
Intraoperative morphine IV, mg & $0.3 \pm 0.4$ & $0.8 \pm 2$ & \\
Ketorolac dose in the first 24 h postop, mg & $69.8 \pm 50.8$ & $69.0 \pm 74.9$ & 0.97 \\
Ambulation in the first 12 h postop, $\mathrm{n} / \mathrm{n}$ & $58 / 58$ & $7 / 10^{*}$ & 0.014 \\
Group TVH/PVS (groups 3 and 4) & ITO (n=40) & IVM (n=13) & P \\
\hline Intrathecal morphine, mg & $1.0 \pm 0.2$ & 0 & N/A \\
Intrathecal fentanyl, $\mu \mathrm{g}$ & $46 \pm 10$ & 0 & N/A \\
Intraoperative fentanyl IV, $\mu \mathrm{g}$ & $45 \pm 41$ & $302 \pm 114$ & \\
Intraoperative morphine IV, mg & $0.3 \pm 0.5$ & $3.1 \pm 6.2$ & \\
Ketorolac dose in the first 24 h postop, mg & $103 \pm 53$ & $32 \pm 61$ & $<0.01$ \\
Ambulation in the first 12 h postop, $\mathrm{n} / \mathrm{n}$ & $39 / 40$ & $10 / 13^{*}$ & 0.015 \\
\hline
\end{tabular}

Data presented as mean $\pm S D$ unless otherwise indicated. ${ }^{*} P<0.05$ Intraoperative morphine and fentanyl: The doses of opioids given for intraoperative analgesia during general anesthesia. Intrathecal morphine and fentanyl: The doses of each opioid given as part of the intrathecal opioid (ITO) injection. Ambulation: The number of patients able to move out of bed in the first 12 h postoperatively (postop). IV Intravenous; IVM Intravenous morphine; N/A Not applicable 


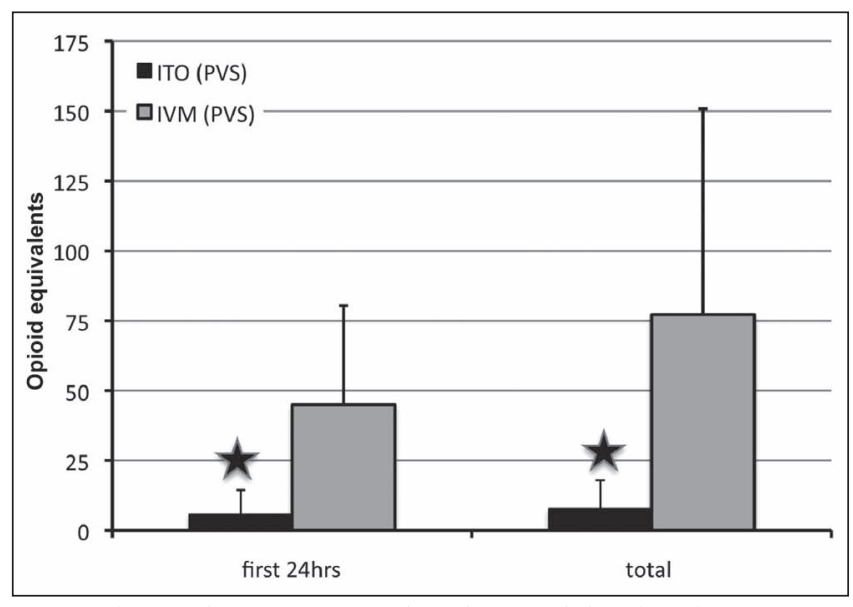

Figure 1) Opioid consumption in the pubovaginal sling (PVS) group. Data presented as mean $\pm S D$. Opioid equivalents $=1 \mathrm{mg}$ morphine. Star symbol indicates $P<0.01$. hrs Hours; ITO Intrathecal opioid (group 1); IVM Intravenous morphine (group 2)

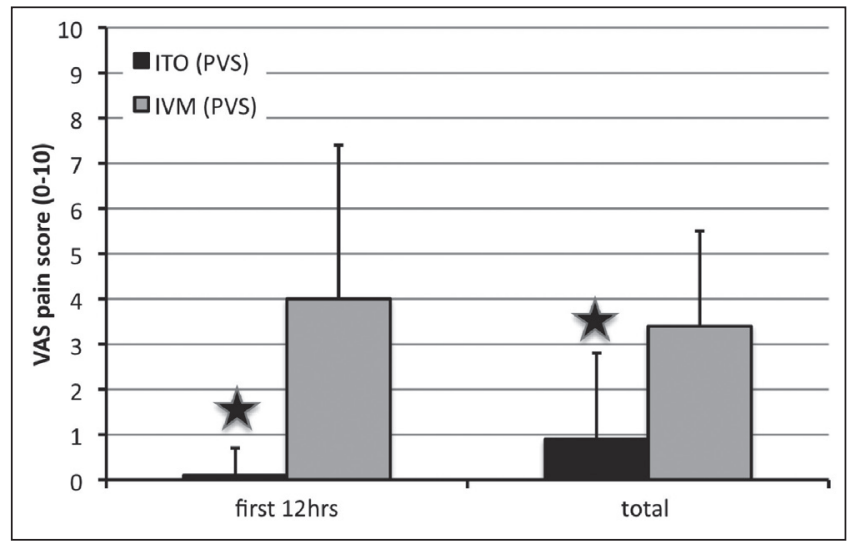

Figure 2) Visual analogue scale (VAS) pain scores $(0=$ no pain, $10=$ worst pain) in the pubovaginal sling (PVS) group. Data presented as mean \pm SD. Star symbol indicates $P<0.01$. hrs Hours; ITO Intrathecal opioid (group 1); IVM Intravenous morphine (group 2)

significantly lower $(\mathrm{P}<0.01)$ in the ITO group $(0.1 \pm 0.6)$ than in the IVM group $(4.0 \pm 2.7)$ (Figure 2$)$. The time to the first postoperative opioid dose was significantly longer in the ITO group than in the IVM group (Figure 3). Patients in the IVM group received significantly more $(\mathrm{P}<0.01)$ postoperative opioids in the first $24 \mathrm{~h}(44.9 \pm 35.5$ morphine equivalents) than the patients in the ITO group $(5.7 \pm 8.7$ morphine equivalents) (Figure 1). As adjuvant to the opioid analgesia, the ITO and IVM groups received similar amounts of IV ketorolac in the first $24 \mathrm{~h}(69.8 \pm 50.8 \mathrm{mg}$ and $69.0 \pm 74.9 \mathrm{mg}$, respectively).

Patients were discharged no sooner than $24 \mathrm{~h}$ after the procedure, with an average of $30 \mathrm{~h}$ after the procedure in both groups. The length of hospitalization did not differ between the treatment groups. The patients in the ITO group did not report pain during the nursing assessment on the floor until $23.7 \pm 6.1 \mathrm{~h}$ postprocedure, whereas the patients in the IVM group reported pain $7.0 \pm 9.6 \mathrm{~h}$ postprocedure $(\mathrm{P}<0.01)$. The VAS pain score before discharge from hospital was $0.9 \pm 1.9$ in the ITO group and $3.4 \pm 2.1$ in the IVM group $(\mathrm{P}<0.01)$.

A comparison of American Society of Anesthesiologists (ASA) scores revealed a slightly higher ASA score in the IVM group than in the ITO group (Table 2, $\mathrm{P}=0.02$ ), indicating a higher prevalence of diabetes, obesity and chronic obstructive pulmonary disease in the IVM group. However, secondary analysis of all variables (VAS scores, opioid equivalents, opioid timing, ketorolac dosing, ambulation and side effects) were unchanged in statistical significance after using ANCOVA with the ASA rating as a covariate.

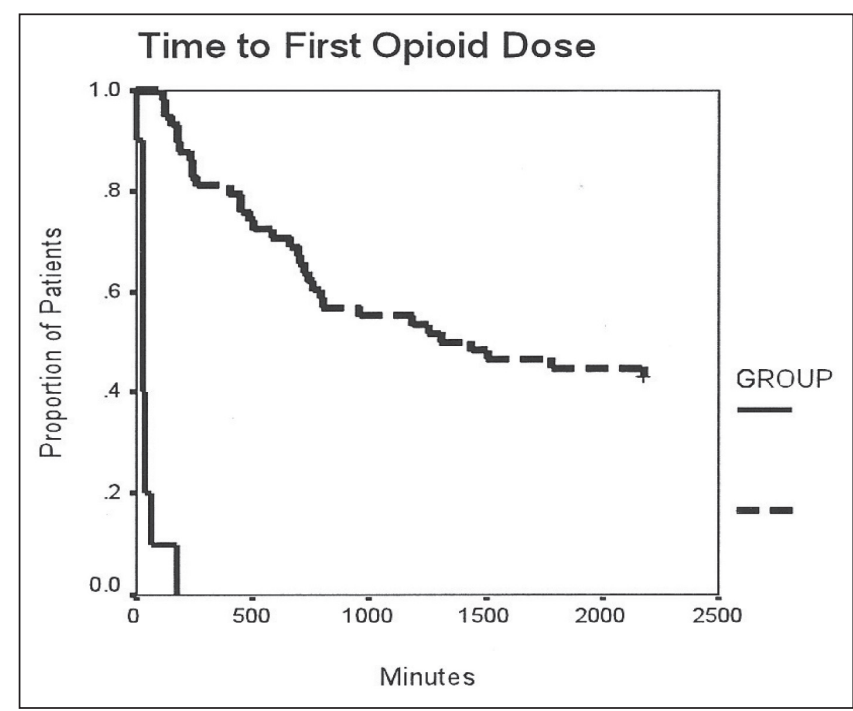

Figure 3) Timing of opioid dosing in the pubovaginal sling (PVS) group. Kaplan-Meier analysis of time to first opioid dose from intrathecal analgesia placement/surgical incision to administration of medication in minutes. Intrathecal opioid group - group 1, intermittent (dashed) line; Intravenous morphine group - group 2, solid line

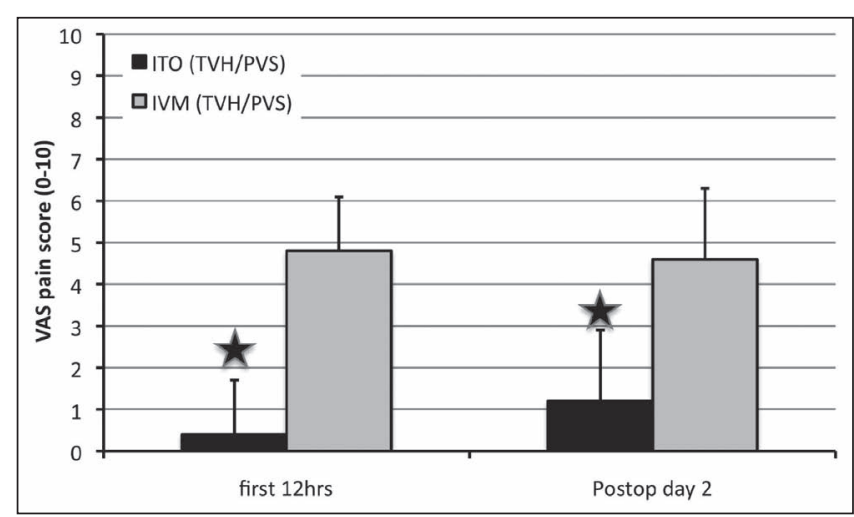

Figure 4) Visual analogue scale (VAS) pain scores ( $0=$ no pain, $10=$ worst pain) in the total vaginal hysterectomy with pubovaginal sling (TVH/ PVS) group. Data presented as mean \pm SD. Star symbol indicates $P<0.01$. hrs Hours; ITO Intrathecal opioid (group 1); IVM Intravenous morphine (group 2); postop Postoperative

\section{Results for TVH/PVS surgery (groups 3 and 4)}

There were a total of 40 patients in the ITO group and 13 patients in the IVM group. The ITO (TVH/PVS) group received $1.04 \pm 0.16 \mathrm{mg}$ morphine and $46 \pm 10 \mu \mathrm{g}$ fentanyl intrathecally. There were no differences in OR and PACU time between the IVM and ITO groups. In general, more effective pain relief was observed (Table 4 and Figure 4) in patients receiving ITOs. The worst VAS pain score in the first $12 \mathrm{~h}$ was significantly lower $(\mathrm{P}<0.01)$ in the ITO group $(0.4 \pm 1.3)$ than in the IVM group (4.8 \pm 3.4$)$. The VAS pain score on postoperative day 2 was better in the ITO group $(1.2 \pm 1.7)$ than in the IVM group $(4.6 \pm 2.8)(\mathrm{P}<0.01)$. The time to first postoperative opioid dose was significantly longer in the ITO group than in the IVM group (Figure 5). Patients in the IVM group received significantly more $(\mathrm{P}<0.01)$ postoperative opioids during the $48 \mathrm{~h}$ observation time (postoperative day 1: 97.6 \pm 33.6 morphine equivalents; postoperative day $2: 32.6 \pm 26.5$ morphine equivalents; for a total of $130.2 \pm 49.8$ morphine equivalents) than the patients in the ITO group (postoperative day 1: $6.6 \pm 11.0$ morphine equivalents; postoperative day 2: 8.0 \pm 5.8 morphine equivalents; for a total of 14.6 \pm 15.0 morphine equivalents) (Figure 6). As an adjuvant to opioid analgesia, the ITO 


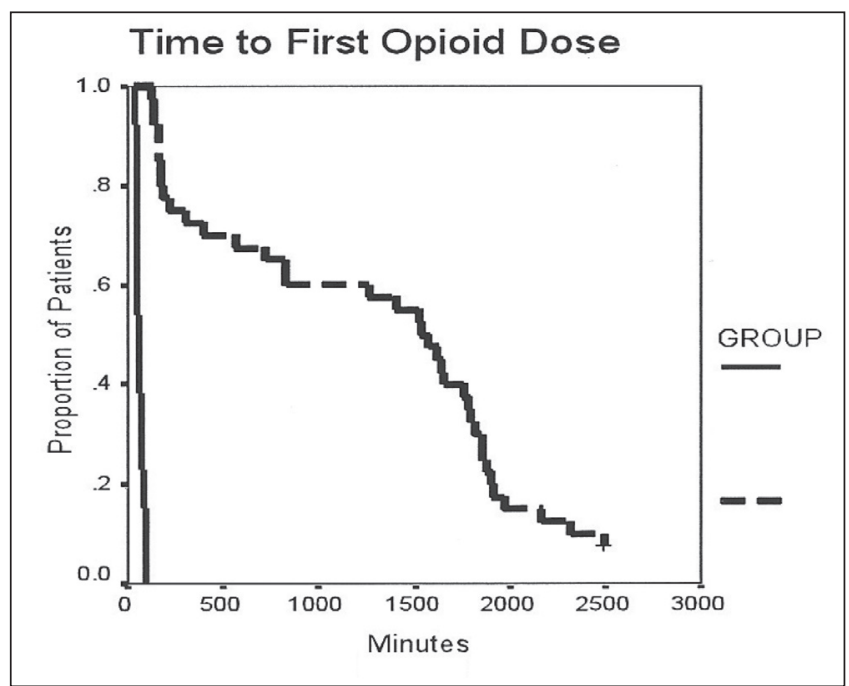

Figure 5) Timing of opioid dosing in the total vaginal hysterectomy with pubovaginal sling group. Kaplan-Meier analysis of time to first opioid dose from intrathecal analgesia placement/surgical incision to administration of medication in minutes. Intrathecal opioid group - group 1, intermittent (dashed) line; Intravenous morphine group - group 2, solid line

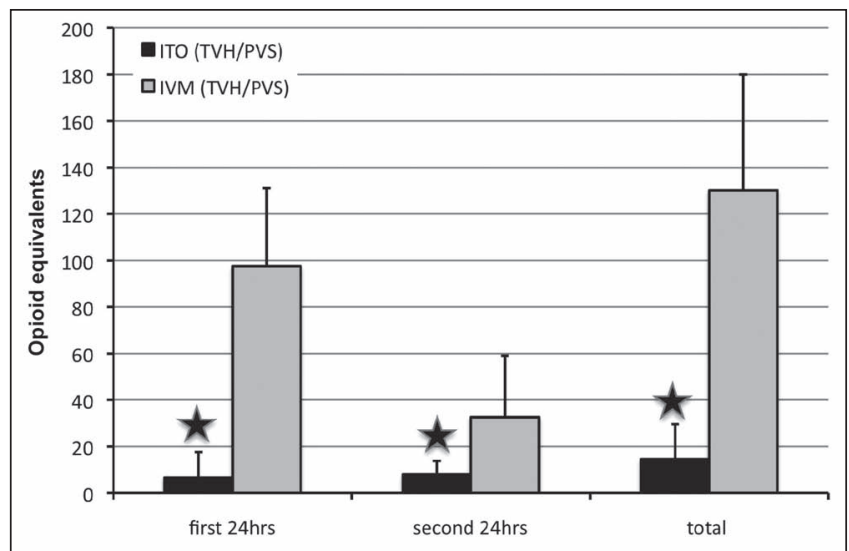

Figure 6) Opioid consumption in the total vaginal hysterectomy with pubovaginal sling (TVH/PVS) group. Opioid equivalents = $1 \mathrm{mg}$ morphine . Data presented as mean \pm SD. Star symbol indicates $P<0.01$. hrs Hours; ITO Intrathecal opioid (group 1); IVM Intravenous morphine (group 2)

and IVM group IV ketorolac in the first $24 \mathrm{~h}$ was $103 \pm 53 \mathrm{mg}$ and $32 \pm 61 \mathrm{mg}$, respectively. Patients were discharged after more than $40 \mathrm{~h}$ postprocedure with a similar length of hospitalization in both groups. The patients in the ITO group did not report pain during the nursing assessment on the floor until $31.3 \pm 13.2 \mathrm{~h}$ postprocedure, whereas the patients in the IVM group reported pain $5.8 \pm 8.4 \mathrm{~h}$ postprocedure $(\mathrm{P}<0.01)$.

The need for additional postoperative opioids was dramatically lower in the ITO patients for both procedures (groups 1 and 3) compared with patients in the IVM groups (Table 5). After undergoing PVS (group 1), 29 patients received the single-shot opioid injection and did not require any other opioids for analgesia during their entire hospitalization. After TVH/PVS (group 3), 23 patients did not require additional opioids after intrathecal morphine in the first $24 \mathrm{~h}$ postoperatively, and three patients did not require any additional opioids before hospital discharge.

Occurrence and severity of opioid-related side effects

In general, more opioid related side effects (Table 6) were observed in the ITO groups (groups 1 and 3). The most common side effect observed
TABLE 5

Patients who did not require additional opioids postoperatively (postop)

\begin{tabular}{|c|c|c|c|c|}
\hline & $\begin{array}{l}\text { Group 1: } \\
\text { ITO } \\
\text { (PVS) }\end{array}$ & $\begin{array}{l}\text { Group 2: } \\
\text { IVM } \\
\text { (PVS) }\end{array}$ & $\begin{array}{l}\text { Group 3: } \\
\text { ITO (PVSI } \\
\text { TVH) }\end{array}$ & $\begin{array}{l}\text { Group 4: } \\
\text { IVM (PVSI } \\
\text { TVH) }\end{array}$ \\
\hline $\begin{array}{l}\text { Patients who did not require } \\
\text { additional opioids in the } \\
\text { first } 24 \mathrm{~h} \text { postop, } \mathrm{n} / \mathrm{n}\end{array}$ & $29 / 58$ & $0 / 10$ & $23 / 40$ & 0/13 \\
\hline $\begin{array}{l}\text { Patients who did not require } \\
\text { additional opioids in the } \\
\text { second } 24 \mathrm{~h} \text { postop, } n / n\end{array}$ & - & - & $3 / 40$ & $0 / 13$ \\
\hline
\end{tabular}

ITO Intrathecal opioid; IVM Intravenous morphine; PVS Pubovaginal sling; TVH Total vaginal hysterectomy

TABLE 6

Occurrence and severity of opioid-related side effects

\begin{tabular}{lcccccr}
\hline & $\begin{array}{c}\text { Group 1: } \\
\text { ITO } \\
\text { (PVS) }\end{array}$ & $\begin{array}{c}\text { Group 3: } \\
\text { ITO } \\
\text { (PVS/TVH) }\end{array}$ & $\begin{array}{c}\text { ITO } \\
\text { total }\end{array}$ & $\begin{array}{c}\text { Group 2: } \\
\text { IVM } \\
\text { (PVS) }\end{array}$ & $\begin{array}{c}\text { Group 4: } \\
\text { IVM } \\
\text { (PVS/TVH) }\end{array}$ & $\begin{array}{c}\text { IVM } \\
\text { total }\end{array}$ \\
\hline Patients & 58 & 40 & 98 & 10 & 13 & 23 \\
$\begin{array}{l}\text { Respiratory } \\
\quad \text { depression }\end{array}$ & 0 & 1 & 1 & 3 & $2^{*}$ & 5 \\
Pruritus & 11 & 15 & $26(27)$ & 2 & 2 & $4(17)$ \\
PONV & 13 & 15 & $28(29)$ & 4 & $9^{*}$ & $13(56)$ \\
Sedation & 6 & 6 & $12(12)$ & 3 & 3 & $6(26)$
\end{tabular}

Data presented as $n$; percentages are in brackets. ${ }^{*} P<0.05$. ITO Intrathecal opioid; IVM Intravenous morphine; PONV Postoperative nausea and vomiting; PVS Pubovaginal sling; TVH Total vaginal hysterectomy

in the analysis was pruritus, with an incidence of $27 \%$ in the ITO group and $17 \%$ in the IVM group. In all patients, the pruritus was easily controlled with diphenhydramine. None of the patients required further intervention. Postoperative nausea or vomiting occurred with similar frequency in both treatment groups for both surgical interventions. The apparently higher occurrence of postoperative nausea and vomiting in the IVM patients might be explained by the small sample size and might not truly reflect statistical difference. All patients received intraoperative antiemetics independently of the analgesic approach. Sedation, as noted by the nursing staff, was never rated as severe and did not require intervention in any of the groups. The increased incidence of sedation in the IVM group might have been related to increased opioid consumption.

The most severe opioid-related side effect - respiratory depression occurred more frequently in the IVM group than in the ITO group. However, in all instances, respiratory depression was recognized early and intervention with either opioid dose reduction or naloxone resolved it without further complications. A single event of respiratory depression in the ITO group occurred because of failure to start the naloxone infusion as ordered, which supports the importance of the IV naloxone infusion to ensure safety of this technique. Specifically, $7 \mathrm{~h}$ after intrathecal injection, the patient became bradypneic (respiratory rate 10 breaths/min) and somnolent. After a naloxone bolus $(0.2 \mathrm{mg})$ followed by a continuous naloxone infusion, the situation resolved. More frequently, respiratory depression secondary to opioid analgesia was observed in the IVM group in five patients. One patient required a naloxone bolus $(0.4 \mathrm{mg})$ for reversal of the respiratory depression. Pulse oximetry was not routinely used in the nonintrathecal analgesia patients. Sedation was the predominant sign of respiratory compromise associated with opioid overdose.

\section{DISCUSSION}

Data from the present retrospective chart review indicated that highdose intrathecal morphine provided excellent postoperative analgesia after major pelvic surgery. The postoperative analgesia was clearly 
superior to standard IV opioid analgesic therapy. The combination of high-dose ITO with IV naloxone controlled opioid-related side effects and did not affect the analgesia.

High-dose intrathecal morphine has been used to control pain for three decades. First reported in 1979 by Cousins et al (9) and Sami et al (10), $1 \mathrm{mg}$ to $2 \mathrm{mg}$ of morphine given intrathecally controlled cancerrelated pain for up to $27 \mathrm{~h}$ in opioid-tolerant patients without causing respiratory depression. However, because this method was more often used for postoperative analgesia in opioid-naive patients, life-threatening respiratory depression was observed (11-15). The seriousness of the induced respiratory depression was related to the dose of ITOs (16). The incidence of late respiratory depression is reported to be $4 \%$ to $7 \%$ for patients receiving intrathecal morphine $(0.8 \mathrm{mg}$ to $2 \mathrm{mg})$, compared with $0.25 \%$ to $0.4 \%$ for those receiving epidural morphine $(2 \mathrm{mg}$ to $4 \mathrm{mg}$ ) (3). Lower doses of intrathecal morphine ( $0.3 \mathrm{mg}$ to $0.4 \mathrm{mg}$ ) are linked to minimal risk of respiratory depression $(16,17)$. In the absence of clear dosing guidelines, ITOs were labelled as having a disturbingly high frequency of respiratory depression and it was believed that lower doses still provided adequate postoperative analgesia (18). Chadwick and Ready (19) studied the analgesic effect of $0.3 \mathrm{mg}$ to $0.5 \mathrm{mg}$ intrathecal morphine after caesarean section and reported that $78 \%$ of the patients experienced more than $20 \mathrm{~h}$ of sufficient analgesia. These findings differ from our analysis and may be explained by the combined use of ITOs with local anesthesia in obstetrics and labour analgesia. Lower doses of intrathecal morphine were added to neuraxial anesthesia with local anesthesia, thus potentiating the analgesic effect and conferring a possible advantage of pre-emptive analgesia, which differed from our study $(20,21)$.

In a recent meta-analysis (22) of randomized trials assessing the benefits and risks of intrathecal morphine without local anesthetic, the opioid-sparing effects of ITOs for abdominal surgery were consistently apparent. In an editorial, Stoelting (23) encouraged the anesthesia community to consider ITOs as the preferable route for opioid-based analgesia and to develop a new attitude toward this underused modality. Leading by example, his group published a retrospective study of nearly 6000 patients who received ITOs for postoperative pain (4). The morphine doses ranged from $0.2 \mathrm{mg}$ to $0.8 \mathrm{mg}$. Patients were very satisfied with the pain control, and side effects were easily managed, with a $3 \%$ incidence of respiratory depression. The duration of the observed analgesia lasted more than $23 \mathrm{~h}$ when high-dose intrathecal morphine was used, which confirmed the observation from previous studies (24). When compared with low-dose intrathecal morphine without naloxone, our approach provided equal, if not superior, analgesia with fewer opioid-related side effects $(25,26)$.

It is possible that the postoperative IV naloxone infusion contributed to the analgesia observed in the ITO group. An enhancement of opioid analgesia by opioid antagonists has been shown in animal models and suggested as a possible treatment for opioid-resistant pain $(27,28)$. A few studies (29-31) conducted in humans suggested a paradoxical opioid enhancement by opioid antagonists. Although the etiology of this effect is unknown, one explanation advocates that opioids have both an inhibitory (analgesic) effect at larger doses and an excitatory (antianalgesic) effect at very low doses. Thus, the addition of low doses of opioid antagonists to opioid agonists produces inhibition of the excitatory effect of opioids and enhances the opioid inhibitory effect (28). It is less likely that our patients experienced an opioid-enhanced effect from the naloxone infusion because the dose of naloxone in our study was much higher than suggested for analgesic enhancement (28).

As a single-shot intrathecal technique with long-lasting analgesia, this approach offers many advantages compared with other methods (catheter peripheral nerve blocks, epidural catheter or IVPCA). Technically, the intrathecal injection is easier to perform than peripheral nerve blocks or epidural catheter placement, and does not need additional equipment such as pumps, ultrasound equipment or a nerve stimulator. The single-shot approach precludes the risk of catheter dislodgement or infection. An important finding in our study was the ease of early ambulation in patients receiving high-dose intrathecal morphine. With good analgesia and no additional equipment needed, the ability to ambulate was obviously better. However, based on the available data and as a limitation of the retrospective analysis, it is unclear whether patients ambulated better because of superior analgesia or other factors. However, this observation alone should make this technique worthy of consideration if early ambulation is essential for surgical success, such as in total joint replacement or in patients at a high risk for deep vein thrombosis. As described in several publications, intrathecal morphine is very efficient method for postoperative analgesia after orthopedic procedures $(1,32,33)$. However, only low-dose regimens have been used, analgesia has been limited and pruritus was a major side effect affecting patient comfort $(32,33)$.

The prophylactic administration of IV naloxone after neuraxial administration of opioids is also not a new idea. As described by Dailey et al in 1985 (34) and Rawal et al in 1986 (35), a continuous IV naloxone infusion was used for intrathecal and epidural morphine as prophylaxis to avoid opioid-related side effects. When used for moderate doses of epidural morphine, naloxone partially reversed the opioidrelated analgesia in a dose-related manner and did not control opioidrelated side effects (26). Low doses of opioid antagonist (naloxone $48 \mu \mathrm{g} / \mathrm{h}$ ) were insufficient to control ITO-related side effects (36). These findings, therefore, differed from our study because we used very high doses of intrathecal morphine and a high-dose naloxone infusion, which effectively controlled the occurrence of toxic opioid side effects, such as respiratory depression, without reversing the analgesia. Our regimen also appeared to control minor opioid side effects such as nausea and pruritus.

When used for labour analgesia, $1 \mathrm{mg}$ intrathecal morphine induced excellent and long-lasting analgesia, and IV naloxone significantly decreased the incidence of opioid-related side effects, especially pruritus and respiratory depression, without affecting analgesia (34). Using the same approach as Dailey et al (34) for labour analgesia, our investigation confirmed the excellent pain relief provided by highdose intrathecal morphine combined with IV naloxone. As in labour pain, the naloxone infusion did not affect postoperative analgesia. Opioid-related side effects were significantly reduced by IV naloxone without affecting analgesia. The single occurrence of respiratory depression in our analysis related to a failure to start the naloxone infusion. This underlines the importance of continuous IV naloxone administration for the safety of the described technique. It is crucial that any discontinuation of naloxone infusion is avoided and that problems (eg, pump failure, loss of peripheral access or subcutaneous infiltration) are immediately noted and corrected. The effect of naloxone on controlling opioid-related side effects has been found to be dose dependent (37). Based on our data, we concluded that the naloxone dose of $5 \mu \mathrm{g} / \mathrm{kg} / \mathrm{h}$ is well tolerated and sufficient to reliably control opioid side effects.

Using a naloxone infusion prophylactically for opioid-related side effects might not be a risk-free method. Naloxone has been well studied as a competitive opioid antagonist for its ability to control opioidrelated side effects. After caesarean section, the incidence of pruritus is reduced by low-dose IV naloxone (38). It is not clear whether the opioid antagonistic effect on pruritus, postoperative nausea and vomiting, urinary retention and analgesia is dose dependent $(38,39)$. Serious possible side effects associated with IV naloxone have been well documented. Not only could naloxone affect the analgesic potency of the opioid-based method (37), it could also induce opioid withdrawal in susceptible patients. We did not observe any reduction in pain control caused by the opioid antagonist. It is beyond the scope of the present investigation to explain this observation. To minimize the possibility of inducing opioid withdrawal with continuous naloxone infusion, we screened our patient collective for evidence of chronic opioid use or opioid tolerance. We do not recommend this approach in opioid-tolerant patients.

Patients on anticoagulation would not be candidates for neuraxial injections according to the American Society of Regional Anesthesia 
recommendations (40). We do not perform neuraxial injections on patients receiving systemic anticoagulation because of the increased risk of development of an epidural hematoma. Therefore, patients on systemic anticoagulation were excluded from our analysis, as described in the Methods section.

In the present study, ITO was not combined with local anesthesia. All patients received general anesthesia for the surgical procedure. Therefore, a synergistic effect of ITOs and local anesthesia, as suggested by Eberle and Norris (41), can be excluded.

There are obvious limitations of data interpretation in our investigation. The retrospective analysis limits the interpretation of data because of the inability to standardize anesthesia and postoperative management of all patients. The patient selection for each group was performed in a nonrandomized manner, based on patient self-selection or pre-existing comorbidities. Because of the lack of randomization, selection bias must be considered and data collection may have led to information bias. The control group was smaller than the treatment group. Based on the nonstandardized approach, we observed a higher dose of ketorolac in the ITO (TVH/PVS) group compared with the IVM group. However, it is unlikely that the differences in analgesia and opioid consumption are solely explained by the difference in nonsteroidal anti-inflammatory drug consumption. It is more likely that the dose of ketorolac was limited in this patient population because of pre-existing renal disease or a history of bleeding disorder. With regard to assessment of pain, the VAS is a less-than-perfect method of pain assessment; however, it is the current clinical standard and the most commonly used scale. Because the data were analyzed retrospectively, we did not have the option to test resting and evoked pain control. Because we observed a significant difference in patient ambulation, we believe that the difference expressed in pain control measured by a VAS reflected true differences. Additionally, the retrospective approach did not allow us to systematically assess the incidence and severity of other opioid-related side effects such as constipation or urinary retention. In future clinical trials, we would limit the opioid selection available for postoperative pain control and breakthrough pain and use standardized IVPCA for all patients (ITO and IVM) to exclude the effect of nursing-dependent factors on opioid timing and consumption.

Recently, practice guidelines for the administration of neuraxial opioids have been published (42). According to the guidelines, the lowest efficacious dose of neuraxial opioid should be used to minimize the risk of respiratory depression. The guidelines strongly agree that the incidence of respiratory depression is increased when higher doses of ITOs are administered (42). Our approach of high-dose, singleinjection ITO combined with concomitant IV naloxone infusion for $24 \mathrm{~h}$ postoperatively is not addressed by these recent practice guidelines. We hypothesize that preventing respiratory depression from the initial hours postoperatively by using a concomitant IV naloxone infusion may be much safer than waiting and diagnosing respiratory depression when it occurs. It might be the safest way to administer a neuraxial opioid because the most feared complication - respiratory depression - is already appropriately addressed and prevented. Clearly, additional prospective clinical studies are necessary to determine the incidence, if any, of postoperative respiratory depression.

The goal of the present retrospective chart review was to document the safety and efficiency of the described technique for postoperative pain control after major pelvic surgery. Our findings do not allow recommendations concerning the optimal dose range for the described technique. Guidelines for the use of neuraxial opioids only recommend the use of the lowest effective neuraxial opioid dose (42). However, no data for a dose-response titration are available. Using a meta-analysis of 27 randomized clinical trials, Meylan et al (22) did not find evidence of a linear dose responsiveness of beneficial and harmful opioid-induced effects. In another meta-analysis, Gehling and Tryba (16) found that higher doses of ITOs in combination with spinal anesthesia were more prone to significant opioid-related side effects, confirming the assumption that local anesthesia and ITOs potentiate one another $(16,20,21,41)$. Further studies will be required to find the optimal intrathecal morphine dose range and to select patient criteria to predict the most effective dose range with the lowest side effect profile. Based on our analysis, and on the study by Dailey et al (34), we found that a single-injection intrathecal morphine dose of $1.0 \mathrm{mg}$ to $1.4 \mathrm{mg}$ appeared to be effective for lower abdominal and pelvic surgery in female and male patients (5). Further studies will also be needed to document the advantages of high-dose neuroaxial opioid analgesia for other surgical indications.

\section{SUMMARY}

High-dose ITOs combined with IV naloxone provided excellent analgesia following pelvic surgery. The IV naloxone appeared to control opioid side effects without interfering with analgesia. No serious adverse events were noted, although a much larger study is needed to rule out any risk of serious respiratory depression. Future studies of the combination of high-dose ITOs with IV opioids using a prospective, randomized clinical trial are warranted. This analgesic technique will not be ready for widespread use until these prospective clinical studies have been completed.

ACKNOWLEDGEMENTS: The authors thank Pikeville Medical Center, especially the Department of Anesthesiology, for their technical assistance and support of this project, and in particular Mr Chris Altman (Chief CRNA) and Ben Cornette (Anesthesia Assistant) for the helpful discussions and encouragement. Additionally, they thank Dr Jonathan Korshin for his efforts and contributions to the development of the technique.

\section{APPENDIX - STANDARD ORDERS FOR HIGH-DOSE INTRATHECAL OPIOIDS AT PIKEVILLE MEDICAL CENTER}

\begin{tabular}{|c|}
\hline $\begin{array}{l}\text { DATE } \\
\text { INTRATHECAL NARCOTIC ORDERS-NARCAN }\end{array}$ \\
\hline Narcotic: Morphine __ mg Fentanyl __ mcg at___ on __ \\
\hline $\begin{array}{l}\text { 1. Maintain IV access for } 22 \text { hours after the narcotic dose. Call anesthesia for questionable IVs. } \\
\text { 2. Run naloxone infusion ( } 10 \text { to } 20 \mathrm{mg} \text { in } 500 \mathrm{ml}=20 \text { to } 40 \mathrm{mcg} / \mathrm{ml}) \text { at } 5 \mathrm{mcg} / \mathrm{kg} / \mathrm{hr}= \\
\text { piggyback until } \\
0.4 \mathrm{mg} \text { ampule available on the floor. } \\
(22 \text { hours after intrathecal dose }) \text { then discontinue. Have Narcan } \\
\mathrm{ml} / \mathrm{hr}\end{array}$ \\
\hline $\begin{array}{l}\text { 3. Continuous pulse oximetry at bedside. Call if } \mathrm{SpO} 2 \text { is less than } 92 \% \text {. Discontinue } 24 \text { hours after bolus dose. } \\
\text { Oxygen } 2-3 \mathrm{~L} / \text { min via } \mathrm{NC} \text { or } 5-6 \mathrm{~L} / \mathrm{min} \text { via humidified face mask. C-section patients need not have pulse } \\
\text { oximetry and only need supplemental nasal oxygen at } 2-3 \mathrm{~L} / \mathrm{min} \text { when asleep. }\end{array}$ \\
\hline $\begin{array}{l}\text { 4. If respiratory rate is less than } 8 / \text { minute, and the patient is difficult to arouse, give Narcan } 0.4 \mathrm{mg} \text {. ( } 1 \text { ampule) } \\
\text { IV STAT and call anesthesiology. If no response repeat } x 3 \text { doses prn. }\end{array}$ \\
\hline 5. Elevate head of bed 30 degrees minimum at all times. Activity per surgeon. \\
\hline $\begin{aligned} \text { 6. NAUSEA/VOMITING : _Promethazine (Phenergan) } 12.5-25 \mathrm{mg} . \text { IV Q } 6 \text { hours prn. } \\
\text { — Ondansetron (Zofran) } 4 \mathrm{mg} \text {. IV Q } 6 \text { hours prn. }\end{aligned}$ \\
\hline $\begin{aligned} \text { 7. ITCHING: _Butorphanol (Stadol) } 1-2 \mathrm{mg} . \text { IV Q } 1-2 \mathrm{hrs} . \text { prn. } \\
\text { _Diphenhydramine (Benadryl) } 12.5-25 \mathrm{mg} \text {. IV Q 4-6 hrs. prn }\end{aligned}$ \\
\hline 8. Foley catheter to BSD. In and out catheterize prn for urinary retention after $\mathrm{D} / \mathrm{C}$ of foley. \\
\hline $\begin{array}{l}\text { 9. BREAKTHROUGH PAIN: } \\
\text { Butorphanol (Stadol) } 2-4 \mathrm{mg} \text {. IV Q } 1-2 \mathrm{hrs.} \text { prn. } \\
\text { Taking PO well, thelac (Toradol) } 1530 \text { (circle one) mg. IV Q } 6 \text { hrs.x } 4 \text { doses scheduled until } \\
\text { To Ibuprofen } 600 \mathrm{mg} \text {. PO Q } 6 \text { hours scheduled. }\end{array}$ \\
\hline 10. ANXIETY, DISCOMFORT: Diazepam 2-5 mg. 5-10 mg. (circle one) IV/PO Q 3-4 hrs. prn. \\
\hline $\begin{array}{l}\text { 11. NO OTHER NARCOTICS, SEDATIVES TO BE GIVEN WITHOUT THE PERMISSION OF } \\
\text { ANESTHESIOLOGY UNTIL : Date } \frac{\text { Time }}{}\end{array}$ \\
\hline $\begin{array}{l}\text { Form \#: } 702117 \\
\text { Date: } 5-18-07\end{array}$ \\
\hline
\end{tabular}

\section{REFERENCES}

1. Shang AB, Gan TJ. Optimizing postoperative pain management in the ambulatory patient. Drugs 2003;63:855-67.

2. Gottschalk A, Wu CL, Ochroch EA. Current treatment options for acute pain. Expert Opin Pharmacother 2002;3:1599-611. 
3. Gustafsson LL, Schildt B, Jacobson K. Adverse effects of extradural and intrathecal opiates: Report of a nationwide survey in Sweden. Br J Anesth 1982;54:479-83.

4. Gwirtz KH, Young JV, Byers RS, et al. The safety and efficiency of intrathecal opioid analgesia for acute postoperative pain: Seven years' experience with 5969 patients at Indiana University Hospital. Anesth Analg 1999;88:599-604.

5. Rebel A, Sloan PA, Andrykowski M. Postoperative analgesia after radical prostatectomy with high-dose intrathecal morphine and intravenous naloxone: A retrospective review. J Opioid Manage 2009;5:331-9.

6. Aldrete JA. The post-anesthesia recovery score revisited. J Clin Anesth 1995;7:89-91.

7. Hanks GWC, Cherny NI, Fallon M. Opioid analgesic therapy. In: Doyle D, Hanks GWC, Cherny NI, Calman K, eds. Oxford Textbook of Palliative Medicine, 3rd edn. Oxford: Oxford University Press, 2004:316-41.

8. Jackson KC, Lipmann AG. Opioid analgesics. In: Tollison CD, ed. Practical Pain Management, 3rd edn. Lippincott, Williams \& Wilkins, 2001:224.

9. Cousins MJ, Mather LE, Glynn CJ, et al. Selective spinal analgesia. Lancet 1979;1:1141-2.

10. Sami K, Feret J, Harari A, Viars P. Selective spinal analgesia. Lancet 1979;1:1142.

11. Abouleish E. Apnea associated with the intrathecal administration of morphine in obstetrics. A case report. Br J Anaesth 1988;60:592-4.

12. Davies GK, Tolhurst-Cleaver CL, James TL. Respiratory depression after intrathecal narcotics. Anesthesia 1980;35:1080-3.

13. Glynn CJ, Mather LE, Cousins MJ, Wilson PR, Graham JR. Spinal narcotics and respiratory depression. Lancet 1981;2:356-7.

14. Gjessing J, Tomlin PJ. Postoperative pain control with intrathecal morphine. Anesthesia 1981;36:268-76.

15. Jones RDM, Jones JG. Intrathecal morphine: Naloxone reverses respiratory depression but not analgesia. Br Med J 1988;281:645-6.

16. Gehling M, Tryba M. Risks and side-effects of intrathecal morphine combined with spinal anaesthesia: A meta-analysis. Anaesthesia 2009;64:643-51.

17. King GH, Mok MS, Steen SN, Lippmann M. Relief of postoperative pain with low dose intrathecal morphine. Pain 1981;11(Suppl 1):S124.

18. Kalso E. Effect of intrathecal morphine, injected with bupivacaine, on pain after orthopedic surgery. Br J Anaesth 1983;55:415-22.

19. Chadwick HS, Ready LB. Intrathecal and epidural morphine sulfate for postcesarean analgesia: A clinical comparison. Anesthesiology 1988;68:925-9.

20. Ong CK, Lirk P, Seymour RA, Jenkins BJ. The efficiency of preemptive analgesia for acute postoperative pain management: A meta-analysis. Anesth Analg 2005;100:757-73.

21. Woolf CJ, Chong MS. Preemptive analgesia - treating postoperative pain by preventing the establishment of central sensitization. Anesth Analg 1993;77:362-79.

22. Meylan N, Elia N, Lysakowski C, Tramer MR. Benefit and risk of intrathecal morphine without local anaesthetic in patients undergoing major surgery: Meta-analysis of randomized trials. Br J Anesth 2009;102:156-67.

23. Stoelting RK. Intrathecal morphine: An underused combination for postoperative pain management. Anesth Analg 1989;68:707-9.

24. Jacobson L, Chabal C, Brody MC. A dose-response study of intrathecal morphine: Efficacy, duration, optimal dose and side effects. Anesth Analg 1988;67:1082-8.
25. Sarma VJ, Bostroem UV. Intrathecal morphine for the pain relief of post-hysterectomy pain - a double-blind, dose-response study. Acta Anesthesiol Scand 1993;37:223-7.

26. Karaman S, Kocabas S, Uyar M, Zincircioglu C, Firat V. Intrathecal morphine: Effects on perioperative hemodynamics, postoperative analgesia, and stress response for total abdominal hysterectomy. Adv Ther 2006;23:295-306.

27. Crain SM, Shen K-F. Antagonists of excitatory opioid receptor functions enhance morphine's analgesic potency and attenuate opioid tolerance/dependence liability. Pain 2000;84:121-31.

28. Sloan PA, Hamann SR. Ultra low-dose opioid antagonists to enhance opioid analgesia. J Opioid Manage 2006;2:295-304.

29. Cruciani RA, Lussier D, Miller-Saultz D, et al. Ultra-low dose oral naltrexone decreases side effects and potentiates the effect of methadone. J Pain Symptom Manage 2003;25:491-4.

30. Hamann SR, Sloan PA. Oral naltrexone to enhance analgesia in patients receiving continuous intrathecal morphine for chronic pain: A randomized, double-blind, prospective pilot study. J Opioid Mange 2007;3:137-44.

31. Hamann SR, Sloan PA, Witt WO. Low-dose intrathecal naloxone to enhance intrathecal morphine analgesia: A case report. J Opioid Manage 2008;4:251-4.

32. Murphy PM, Stack D, Kinirons B, Laffey JG. Optimizing the dose of intrathecal morphine in older patients undergoing hip arthroplasty. Anesth Analg 2003;97:1709-15.

33. Rathmell JP, Pino CA, Taylor R, Patrin T, Viani BA. Intrathecal morphine for postoperative analgesia: A randomized, controlled, dose-ranging study after hip and knee arthroplasty. Anesth Analg 2003;97:1452-7.

34. Dailey PA, Brookshire GL, Shnider SM, et al. The effects of naloxone associated with the intrathecal use of morphine in labor. Anesth Analg 1985;64:658-66.

35. Rawal N, Schoett U, Dahlstroem B, et al. Influence of naloxone infusion on analgesia and respiratory depression following epidural morphine. Anesthesiology 1986;64:194-201.

36. Connelly NR, Rahimi A, Parker RK. Nalmefene or naloxone for preventing intrathecal opioid mediated side effects in cesarean delivery patients. Int J Obstet Anesth 1997;6:231-4.

37. Gan TJ, Ginsberg B, Glass PS, et al. Opioid-sparing effects of a low-dose infusion of naloxone in patient-administered morphine sulfate. Anesthesiology 1997;87:1075-81.

38. Culebras X, Gaggero G, Zatlouka L, Kern C, Marti RA. Advantages of intrathecal nalbuphine, compared to intrathecal morphine, after cesarean delivery: An evaluation of postoperative analgesia and adverse effects. Anesth Analg 2000;91:601-5.

39. Raffaeli W, Marconi G, Fanelli G, et al. Opioid-related side-effects after intrathecal morphine: A prospective, randomized, double-blind dose-response study. Eur J Anaesthesiol 2006;23:605-10.

40. Horlocker TT, Wedel DJ, Benzon H, et al. Regional anesthesia in the anticoagulated patient: Defining the risks (the second ASRA Consensus Conference on Neuroaxial Anesthesia and Anticoagulation). Reg Anesth Pain Med 2003;28:172-97.

41. Eberle RL, Norris MC. Labour analgesia. A risk-benefit analysis. Drug Saf 1996;14:239-51.

42. Horlocker TT, Burton AW, Connis RT, et al. (ASA Task Force on Neuroaxial Opioids). Practice guidelines for the prevention, detection, and management of respiratory depression associated with neuroaxial opioid administration. Anesthesiology 2009;110:218-30. 


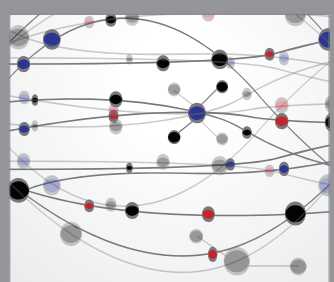

The Scientific World Journal
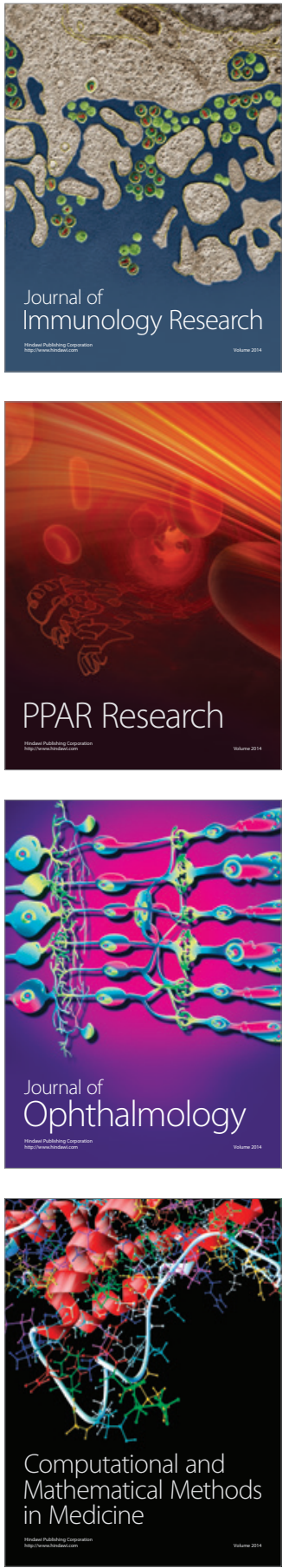

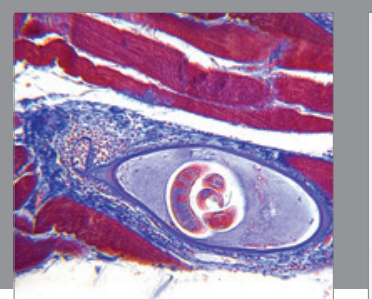

Gastroenterology Research and Practice

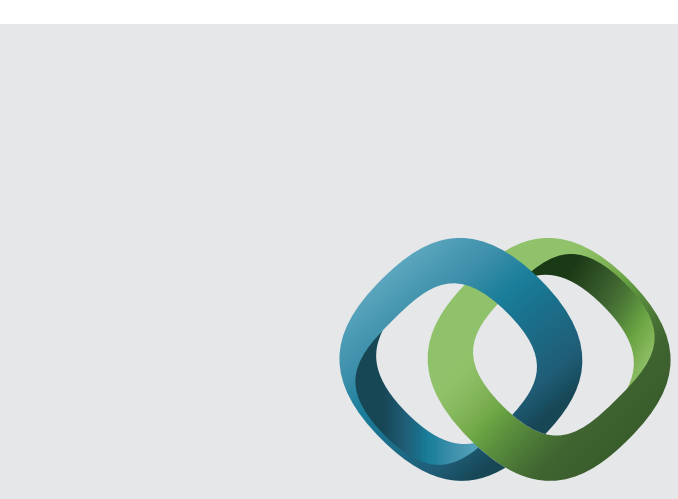

\section{Hindawi}

Submit your manuscripts at

http://www.hindawi.com
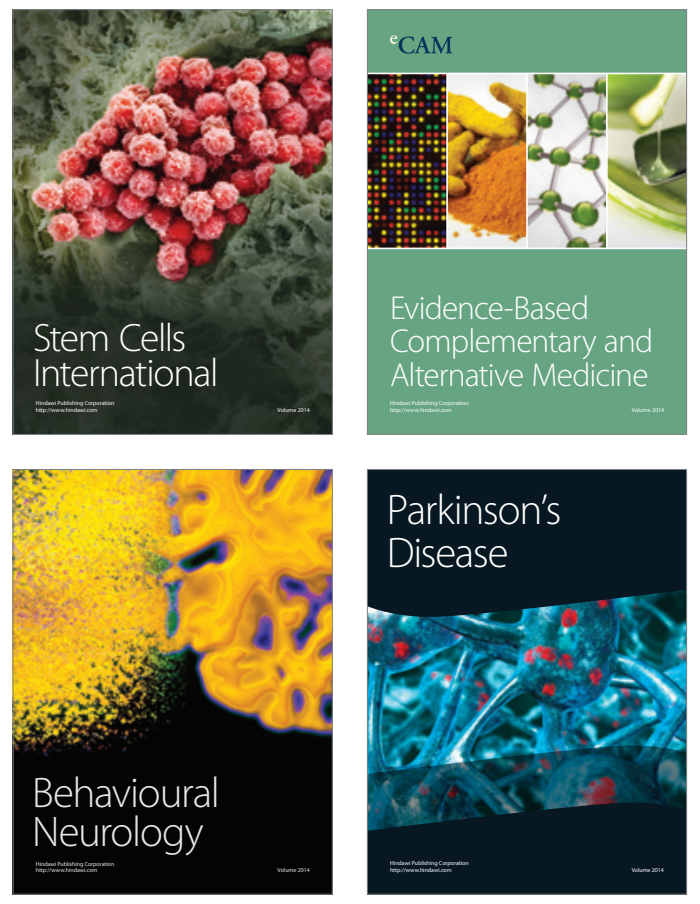
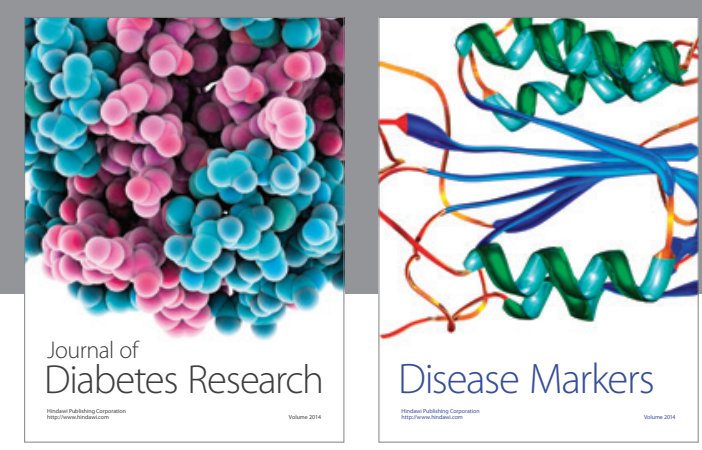

Disease Markers
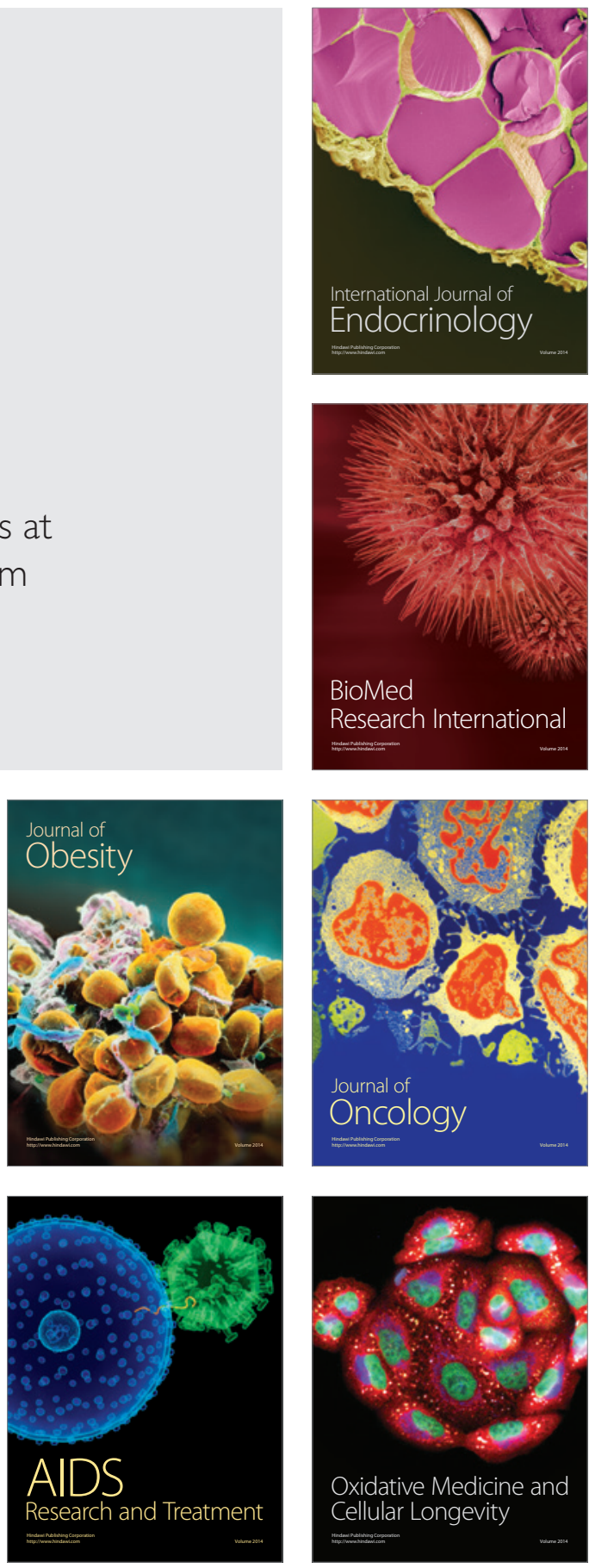